\title{
BMJ Open Neighbourhood environment, sitting time and motorised transport in older adults: a cross-sectional study in Hong Kong
}

\author{
Anthony Barnett, ${ }^{1}$ Ester Cerin, ${ }^{1,2}$ Claudia S-K Ching, ${ }^{2}$ Janice M Johnston, ${ }^{3}$ \\ Ruby S Y Lee ${ }^{4}$
}

To cite: Barnett $A$, Cerin $E$, Ching CS-K, et al. Neighbourhood environment, sitting time and motorised transport in older adults: a cross-sectional study in Hong Kong. BMJ Open 2015;5:e007557. doi:10.1136/bmjopen-2014007557

\section{- Prepublication history} and additional material is available. To view please visit the journal (http://dx.doi.org/ 10.1136/bmjopen-2014007557).

Received 29 December 2014 Revised 25 March 2015 Accepted 13 April 2015

\section{CrossMark}

\footnotetext{
${ }^{1}$ School of Exercise and Nutrition Sciences, Deakin University, Burwood, Victoria, Australia

${ }^{2}$ Institute of Human Performance, The University of Hong Kong, Pokfulam, Hong Kong SAR

${ }^{3}$ School of Public Health, The University of Hong Kong, Pokfulam, Hong Kong SAR

${ }^{4}$ Department of Health, Elderly Health Service, Quarry Bay, Hong Kong
}

Correspondence to Dr Anthony Barnett; anthony.barnett@deakin.edu. au

\section{ABSTRACT}

Objectives: Sitting time is a public health concern. This study examined associations of objectively measured neighbourhood environmental attributes with non-transport sitting time and motorised transport in 484 Hong Kong older adults. Neighbourhood attributes encouraging walking may help older adults replace some sitting time at home and on motorised transport with light-to-moderate-intensity activities such as strolling around the neighbourhood or walking to/from neighbourhood destinations. Thus, we hypothesised environmental attributes found to be related to walking would show associations with non-transport sitting time and motorised transport opposite to those seen for walking.

Design: Cross-sectional.

Setting: Hong Kong, an ultradense urban environment.

Participants: 484 ethnic Chinese Hong Kong residents aged 65+ recruited from membership lists of four Hong Kong Elderly Health Centres representing catchment areas of low and high transport-related walkability stratified by socioeconomic status (response rate: $78 \%$ ).

\section{Primary and secondary outcome measures:}

Attributes of participants' neighbourhood environments were assessed by environmental audits, while nontransport sitting time and motorised transport were ascertained using the International Physical Activity Questionnaire-Long Form (Chinese version).

Results: Daily non-transport sitting minutes were 283 ( $S D=128)$ and motorised transport $23(S D=28)$. Prevalence of signs of crime/disorder, streetlights, public facilities (toilets and benches) and pedestrian safety were independently negatively related, and sloping streets positively related, to sitting outcomes. Places of worship in the neighbourhood were predictive of more, and prevalence of public transit points of less, non-transport sitting. Associations of either or both sitting outcomes with prevalence of food/grocery stores and presence of parks were moderated by path obstructions and signs of crime/ disorder.

Conclusions: The findings suggest that access to specific destinations and relatively low-cost, minimal

\section{Strengths and limitations of this study}

- This is the first study to examine associations of the neighbourhood environment with nontransport sitting and motorised transport in older adults.

- The direct, objective determination of neighbourhood environmental attributes.

- The study assesses sitting time with an internationally validated questionnaire widely used to measure physical activity and sitting time.

- This is a cross-sectional design with exclusive use of self-reports of sitting time.

- The sample included only fully mobile older adults.

impact modifications to the urban form, such as street lighting, public toilets, benches and public transit points, could potentially reduce sitting time and associated negative health outcomes in Hong Kong older adults.

\section{BACKGROUND}

There is evidence of positive associations of adults' sedentary behaviour with all-cause mortality, cardiovascular disease, type 2 diabetes, metabolic syndrome, some cancers and low-grade inflammation, ${ }^{12}$ and negative associations with mental health. ${ }^{3}$ In older adults, positive associations have been found of sedentary behaviour with all-cause mortality, metabolic syndrome, waist circumference, overweightness/obesity, sarcopenia, executive function, bone mineral density and kidney function. ${ }^{4-8}$ Reduction in sedentary behaviour in older adults is, therefore, an important public health objective.

Strong negative associations between sedentary behaviour and light-intensity physical activity, and weaker associations between 
sedentary time and moderate-to-vigorous physical activity have been reported. ${ }^{9}{ }^{10}$ This suggests that increased time spent undertaking light-intensity physical activity is likely to replace sedentary behaviour. There are a number of potential determinants of sedentary behaviour. According to socioecological models of sedentary behaviour, these include the environmental settings in which sedentary behaviour may occur (work, school, home, neighbourhood and transport), individual factors (eg, self-efficacy and preferences) and social environmental factors (eg, social support and social norms). ${ }^{11}$ The neighbourhood environment has been of particular interest due to the large scale and sustainability of its potential influence on behaviour. While there is substantial evidence that, from a public health viewpoint, the neighbourhood environment is an important determinant of physical activity, ${ }^{12-14}$ few studies have examined neighbourhood environmental correlates of sedentary behaviour. Analysis of data on adults from three Western countries found sitting time, the primarily component of sedentary behaviour, ${ }^{15}$ was associated with perceived neighbourhood environment attributes; positively with residential density and negatively with a number of different types of destinations, access to services and aesthetics. ${ }^{16}$ Also, Flemish older adults' television (TV) viewing time was negatively related to presence of cultural facilities, greenery, street lighting and living within moderate distance of facilities, but positively related to feelings of unsafety and absence of noise. ${ }^{17}$

In general, with the exception of residential density, these two studies suggest that environmental attributes that are generally positively associated with walking show a negative association with sedentary behaviours. This is not surprising given the negative association between sedentary time and light activity time, ${ }^{9}{ }^{10}$ and walking being a popular form of light-to-moderate physical activity. ${ }^{18}$ For example, $90 \%$ of habitual walking in 2417 Hong Kong adults was found to be of light intensity. ${ }^{19}$

Van Cauwenberg et $a l \mathrm{~s}^{17}$ appears to be the only study to date to have investigated relationships between characteristics of the neighbourhood environment and a component of sedentary behaviour in older adults. There is a need for further studies in other geographical locations and employing measures of sedentary behaviour that extend beyond TV viewing time, as older adults can spend substantial amounts of time sitting for transportation purposes as well as for other recreational purposes (eg, reading, socialising).

Our study of Hong Kong older adults with no mobility problems investigated relationships between neighbourhood environmental attributes and physical activity (including walking) using internationally comparable measures. We found that the access to specific destinations (eg, parks, recreational facilities) and pedestrian infrastructure were positively related to recreational walking, ${ }^{20}{ }^{21}$ while the prevalence and diversity of destinations were related to walking for transport. ${ }^{22}$ Also, some positive associations of access to destinations with walking ${ }^{22}$ and leisure-time physical activity, ${ }^{20}$ depended on neighbourhood safety and infrastructure attributes being favourable. We hypothesise that environmental attributes positively associated with walking likely decrease time spent at home, reducing TV viewing and other sedentary behaviours. It may also encourage active modes of transport for utilitarian purposes, reducing the use of motorised transport.

Thus, this study examined associations of objectively measured environmental correlates of walking with nontransport sitting time and motorised transport in older adults with no mobility problems residing in Hong Kong, a high-density Asian metropolis. We hypothesised environmental correlates of walking would show associations with non-transport sitting time and motorised transport opposite to those seen for walking, and neighbourhood safety and infrastructure characteristics would moderate relationships between sitting time and destinations.

\section{METHODS}

This study represents secondary analyses of data from a project on environmental correlates of physical activity in Hong Kong Chinese older adults. ${ }^{20-22}$ The project employed the Chinese version of the International Physical Activity Questionnaire-Long Form (IPAQ-LC), ${ }^{23}$ which also provided the non-transport sitting and motorised transport time data we examined in this paper.

\section{Participants and procedure}

In 2007-2008, 484 Cantonese-speaking Chinese Hong Kong residents aged $65+(42 \%$ males; $33 \% 75+$ year old; $13 \%$ with no formal education; $48 \%$ with primary and $39 \%$ with at least secondary education; $0 \%$ car ownership) were recruited from membership lists of 4 out of 18 Hong Kong Elderly Health Centres, established by the Department of Health of the Hong Kong SAR with the aim of providing membership-based comprehensive primary care services to residents aged $65+$ years. These Elderly Health Centres represented catchment areas of low and high transport-related walkability stratified by socioeconomic status (SES; response rate: 78\%). Area SES was defined using census data on median monthly household income and percentage of owner occupiers. District median monthly household income and per cent of owner occupiers ranged from HK\$12 200 and 42\% in the high-walkable, low-SES study areas to HK\$25000 and $62 \%$ in high-walkable, high-SES study areas. ${ }^{24}$ Transport-related walkability was operationalised using data on household, intersection and commercial/service destination densities. The neighbourhood sampling procedure has been described in detail elsewhere. ${ }^{25}$

Eight street blocks with at least 25 residing Elderly Health Centre members were randomly selected without replacement in each of four Elderly Health Centre catchment areas (total of 32 street blocks). Approximately 15 participants with no diagnosed 
cognitive impairment, and with no mobility problems (based on medical assessments), were randomly selected and recruited from each of the 32 blocks via an invitation letter followed up by a phone call. After providing written informed consent, they took part in a $40 \mathrm{~min}$ face-to-face interviewer-administered survey. Participants received grocery vouchers as participation incentives. Environmental audits of the neighbourhoods of residence of the study participants were conducted during daylight (10:00-18:00).

\section{Instruments}

\section{Sociodemographic characteristics}

Data on gender, age and educational attainment were obtained using a short sociodemographic questionnaire.

\section{Sitting}

Last 7-day daily minutes of non-transport sitting and motorised transport were estimated using the IPAQ-LC. ${ }^{23}$ The reliability and validity of the IPAQ-LC among Hong Kong older adults mirrored those of international studies. ${ }^{23}$ For non-transport sitting, participants were required to indicate the time they spent sitting on a usual weekday and a usual weekend day in the past 7 days. The two questions were prefaced by asking participants to consider multiple life domains for the period of sitting being recalled, excluding transport-related sitting (ie, motorised transport). For the purpose of this study, we calculated a weighted estimate of sitting on a typical day by multiplying sitting time on a typical weekday by 5 (days), sitting time on a typical weekend day by 2 and dividing their sum by 7 . The correlation between estimates of sitting on weekday and weekend days was 0.89 . Motorised transport was assessed by asking participants to report the number of days (in the past 7 days) and the usual time on one of those days they travelled in a motor vehicle such as a train, bus, car or tram. As older adults are likely to sit while travelling on public transport (train, tram or bus), these items represent estimates of frequency (days/week) and average daily amount (number of days multiplied by usual time on one of those days divided by 7) of transport-related sitting.

\section{Environmental audits}

Attributes of the neighbourhood environment were gauged using the Environment in Asia Scan ToolHong Kong version (EAST-HK), ${ }^{25}$ a validated environmental audit tool that was developed for use in Hong Kong and other densely populated Asian metropolises. For the purpose of this study, we used dichotomous items (present/absent) on the following categories of destinations: parks (1 item); other recreational areas (4 items); places of worship (1 item); health clinics/services (1 item); entertainment (eg, movie/drama theatre; Hong Kong Jockey Club betting branches; 3 items); public transit point (1 item); non-food retail and services (eg, bank, barber, clothing store; 7 items); food and grocery stores (eg, supermarket, fresh-food market; 4 items) and restaurants (eg, Chinese non-fast food restaurant, Western fast food restaurant; 5 items). Items measuring safety (sign of crime/disorders (4 items); presence of stray animals (1 item); streetlights (1 item); pedestrian safety (3 items)), infrastructure (path obstructions (eg, roadwork, motor vehicles parked on footpaths, hawkers; 4 items); good path conditions (2 items); sloping street (1 item); public services (presence of public toilets and sitting facilities; 2 items) and indoor/covered places for walking (2 items)) and aesthetics/cleanliness (building attractiveness (2 items); natural sights (1 item); trees (1 item); perceptible noise/air pollution (2 items); litter (3 items)) were also employed.

Trained auditors collected data on both sides of each street segment (1536 in total) within a $400 \mathrm{~m}$ roadnetwork distance from the participants' residential blocks $(n=32)$. The average data collection time per street segment was $\sim 11 \mathrm{~min}$. Inter-rater agreement was moderate to perfect. $^{25}$

\section{Data processing and analysis}

\section{Data processing of EAST-HK data}

Environmental data were aggregated by residential block areas representing neighbourhoods. Aggregated scores of safety, infrastructure and aesthetics/cleanliness attributes measured with a single item represented the percentage of street segments within a neighbourhood with the specific attribute, while scores of attributes measured by multiple items represented the percentage of the highest obtainable score averaged across street segments falling within a neighbourhood. For example, given that the highest obtainable score on 'path obstructions' was 4 , an average score of 2.6 across street segments would correspond to $65 \%$ of the maximal score (ie, a score of 65 out of 100). Such operationalisation provides a measure of prevalence of specific environmental characteristics.

Single-item destination categories of parks, health centres/clinics and places of worship were operationalised as being present or absent in a specific neighbourhood (presence/diversity measure). The single-item destination category of public transit points was operationalised as the number of street segments within a neighbourhood with at least one public transit point (prevalence measure). We counted number of street segments with a destination rather than number of destinations per street segment because the latter option is not feasible in ultradense metropolises such as Hong Kong, with extreme levels of commercial/service destination density exceeding 1600 units $/ \mathrm{km}^{2}{ }^{24}$ Diversity measures of multiple-item destination categories (entertainment and recreational) were each operationalised as the number of different types of facilities within the neighbourhood. For example, given that data were collected on four different types of recreational facilities other than parks, diversity scores on this destination category could range from 0 (no recreational facilities) to 4 
(all four different types of facilities present in the neighbourhood). To obtain intensity measures of multiple-item destination categories, the numbers of neighbourhood street segments with specific types of facilities falling within a category (eg, restaurants) were computed and summed up. For example, if a neighbourhood had Western fast food restaurants in five street segments, Chinese non-fast food restaurants in three street segments and no other types of restaurants, it would be assigned a score of 8 on the intensity measure for restaurants.

\section{Data analysis}

Descriptive statistics were computed for all variables. Street block-level (ie, neighbourhood-level) clustering effects defined as intraclass correlation coefficients were estimated for the three outcome variables (nontransport sitting time, and motorised transport sitting time and frequency). Generalised linear models (GLMs) accounting for neighbourhood-level clustering effects were used to examine associations of neighbourhood environmental characteristics with non-transport sitting and motorised transport variables. Gaussian variance and identity link functions were used for average daily minutes of non-transport sitting, while $\gamma$ and negative binomial variance functions were used to model average daily minutes, and frequency of motorised transport (days/week), respectively. The latter two outcomes were modelled using a logarithmic link function. All models were adjusted for gender, educational attainment, age and neighbourhood-level SES. The results from the Gaussian GLMs were expressed as regression coefficients (b) and their 95\% CIs, which are to be interpreted as the increase or decrease in mean non-transport sitting (min/day) associated with a 1 unit increase in the predictor. The results from the $\gamma$ and negative binomial GLMs were expressed as antilogarithms of regression coefficients $\left(\mathrm{e}^{\mathrm{b}}\right)$ and their $95 \%$ CIs, which are to be interpreted as the proportional increase or decrease in mean motorised transport amount $(\mathrm{min} /$ day) or frequency (day/week) associated with a 1 unit increase in the predictor.

A first set of GLMs estimated the independent contribution of sociodemographic, environmental safety, infrastructure and aesthetics/cleanliness covariates, to the explanation of non-transport sitting and motorised transport, using a backward stepwise procedure to exclude non-significant environmental correlates from the GLMs. A second set of GLMs estimated the relationships of single destination variables with non-transport sitting and motorised transport, adjusting for the above sociodemographic covariates and environmental covariates. Separate models estimated two-way interaction effects of destination variables by safety and infrastructure-related environmental attributes identified in previous work. ${ }^{22} 26$

We then examined the associations of all statistically significant (at a 0.05 probability level) destination and other environmental correlates derived from the models described above to decide whether they could be entered in a multiple-predictor model to examine the independent contributions of the identified correlates to non-transport sitting and motorised transport. If there were no multicollinearity issues, all correlates were entered in a GLM, which also included significant covariates and interaction terms. Continuous variables were centred around the mean. Significant interaction terms were probed by estimating associations at values of the moderating environmental attributes 1 SD below and above their mean. ${ }^{27}$ For moderators with a SD greater than the mean, associations at the smallest possible value of the moderating attribute and at $1 \mathrm{SD}$ above its mean were estimated. All analyses were conducted using Stata V.10.1.

\section{RESULTS}

\section{Descriptive statistics}

Participants ( $\mathrm{N}=484)$ reported an average of $283 \pm 128$ daily minutes of non-transport sitting (median $=265$; $\mathrm{IQR}=180$ ), and $23 \pm 28 \mathrm{~min} /$ day (median $=15 ; \mathrm{IQR}=33$ ) and $2.7 \pm 2.5$ days/week (median=2.0; $\quad \mathrm{IQR}=3.0) \quad$ of motorised transport. The neighbourhood-level amount of clustering (ie, per cent of outcome variances explained by neighbourhood-level differences) was $5.6 \%$ for non-motorised sitting (equivalent to a SD of $31 \mathrm{~min} /$ day); $14.2 \%$ for days/week of motorised travel (equivalent to a SD of 0.92 days/week) and $9.7 \% \mathrm{~min} /$ day of motorised travel (equivalent to a SD of $8.70 \mathrm{~min} /$ day).

Public transit points were present in all, and health clinics/services and parks in most, neighbourhoods (table 1). The sampled neighbourhoods had low prevalence of stray animals and signs of crime/disorder. In contrast, streetlights and well-maintained sidewalks were widespread features. All aesthetics-related, as well as other infrastructure-related and safety-related, measures were highly variable across neighbourhoods (table 1 ).

Associations of neighbourhood safety, infrastructure and aesthetic/cleanliness characteristics, with sitting and motorised transport

When adjusting for sociodemographic characteristics, the prevalence of signs of crime/disorder $(b=-13.7$; $95 \%$ CI -26.9 to $-0.44 ; \mathrm{p}=0.043)$, streetlights $(\mathrm{b}=-1.2$; $95 \%$ CI -2.1 to $-0.3 ; \mathrm{p}=0.011$ ) and public facilities (toilets and benches; $\mathrm{b}=-1.4 ; 95 \%$ CI -2.3 to -0.5 ; $\mathrm{p}=0.005$ ), were independently negatively related to nontransport sitting. In contrast, the prevalence of sloping streets was positively related to non-transport sitting ( $\mathrm{b}=0.6 ; 95 \%$ CI 0.2 to $1.0 ; \mathrm{p}=0.006)$ as well as frequency of motorised transport $\left(\mathrm{e}^{\mathrm{b}}=1.007 ; 95 \%\right.$ CI 1.001 to $1.013 ; \mathrm{p}=0.014$ ). For example, residents living in neighbourhoods with $75 \%$ of sloping street segments reported, on average, $45(0.6 \times 75)$ more minutes of nontransport sitting per day than those living in neighbourhoods with no sloping streets. Pedestrian safety was negatively related to daily minutes $\left(\mathrm{e}^{\mathrm{b}}=0.987 ; 95 \%\right.$ CI 0.977 
Table 1 Descriptive statistics of neighbourhood environmental attributes (32 neighbourhoods)

\begin{tabular}{|c|c|c|}
\hline Environmental attributes (theoretical range) & $M(S D)$ & Minimum-maximum \\
\hline \multicolumn{3}{|l|}{ Measures of destination presence/diversity* } \\
\hline Park-presence $(0-1)$ & $0.9(0.3)$ & $0-1$ \\
\hline Recreational destinations-diversity (0-4) & $1.5(0.9)$ & $0-4$ \\
\hline Health clinics/services-presence $(0-1)$ & $0.8(0.4)$ & $0-1$ \\
\hline Places of worship-presence $(0-1)$ & $0.5(0.5)$ & $0-1$ \\
\hline Entertainment destinations-diversity (0-5) & $2.4(0.9)$ & $0-5$ \\
\hline \multicolumn{3}{|l|}{ Measures of destination prevalence } \\
\hline Public transit points $(0-77)$ & $7.4(4.5)$ & $1-22$ \\
\hline Non-food retailers and services (0-539) & $19.7(21.0)$ & $0-80$ \\
\hline Food and grocery stores (0-308) & $13.2(10.7)$ & $0-46$ \\
\hline Restaurants (0-385) & $19.4(20.1)$ & $0-82$ \\
\hline \multicolumn{3}{|l|}{ Infrastructure $\ddagger$} \\
\hline Sloping street $(0-100)$ & $14(22)$ & $0-75$ \\
\hline Public facilities (0-100) & $16(9)$ & $0-36$ \\
\hline Good path conditions (0-100) & $90(7)$ & $62-100$ \\
\hline Path obstructions $(0-100)$ & $17(13)$ & $0-48$ \\
\hline Indoor/covered places for walking (0-100) & $25(12)$ & $0-65$ \\
\hline \multicolumn{3}{|l|}{ Safety $\ddagger$} \\
\hline Stray animals $(0-100)$ & $2(5)$ & $0-20$ \\
\hline Street lights $(0-100)$ & $85(12)$ & $36-100$ \\
\hline Signs of crime/disorder (0-100) & $2(4)$ & $0-12$ \\
\hline Pedestrian safety $(0-100)$ & $55(17)$ & $24-83$ \\
\hline \multicolumn{3}{|l|}{ Aesthetics and cleanliness $\ddagger$} \\
\hline Building attractiveness $(0-100)$ & $48(7)$ & $22-60$ \\
\hline Natural sights $(0-100)$ & $21(29)$ & $0-100$ \\
\hline Trees $(0-100)$ & $35(15)$ & $0-100$ \\
\hline Noise/air pollution $(0-100)$ & $36(34)$ & $0-100$ \\
\hline Litter $(0-100)$ & $21(27)$ & 0-92 \\
\hline
\end{tabular}

to $0.997 ; \mathrm{p}=0.014)$ as well as to frequency of motorised transport $\left(\mathrm{e}^{\mathrm{b}}=0.992 ; 95 \%\right.$ CI 0.986 to $\left.0.999 ; \mathrm{p}=0.023\right)$. Path conditions, indoor/covered places for walking, the presence of stray animals and all aesthetics-related features measured in this study did not significantly contribute to the explanation of non-transport sitting or motorised transport.

\section{Associations of single destination measures with} non-transport sitting and motorised transport, and moderating effects of environmental characteristics

Table 2 shows the associations of single destination measures with sitting variables, adjusted for sociodemographic factors and significant environmental safety, aesthetics and infrastructure covariates. The presence of at least one place of worship in the neighbourhood was predictive of 27.8 more minutes of non-transport sitting as compared with having no access to such type of destination (table 2). It was also predictive of lower frequency, but not total average daily amount, of motorised transport. The prevalence of public transit points was negatively related to non-transport sitting but positively associated with frequency of motorised transport. For example, participants living in neighbourhoods with the highest prevalence of transit points (22 street segments in the $400 \mathrm{~m}$ neighbourhood buffer), accumulated on average 48.2 fewer minutes of non-transport sitting than their counterparts living in an area with a single street segment with a public transit point. No other significant main effects of destination measures on non-transport sitting and motorised transport variables were observed.

Although there were no significant main effects of entertainment destinations diversity and prevalence of food/grocery stores with non-transport sitting (table 2), the prevalence of signs of crime/disorder and path obstructions, respectively, moderated these associations (table 3). Specifically, while no significant association was found between entertainment destinations diversity and non-transport sitting at $1 \mathrm{SD}$ above average levels of signs of crime/disorder, a significant negative relationship was found at the lowest observed score (0) of this environmental attribute. The association of prevalence of food/grocery stores with non-transport sitting was not significant at above average levels, but significant and 
Table 2 Associations of destination measures with non-transport sitting and motorised transport in Hong Kong older adults (main effects)

\begin{tabular}{|c|c|c|c|c|}
\hline Destination measure & Outcome variable & b or $\mathbf{e}^{\mathbf{b}}$ & $95 \% \mathrm{Cl}$ & p Value \\
\hline \multirow{3}{*}{ Park-presence } & NT sitting (min/day) & -0.8 & -9.0 to 7.4 & 0.841 \\
\hline & Motorised transport $(\min / \text { day })^{*}$ & 0.992 & 0.495 to 1.989 & 0.983 \\
\hline & Motorised transport (days/week) & 1.164 & 0.731 to 1.857 & 0.522 \\
\hline \multirow{3}{*}{ Recreational destinations—diversity } & NT sitting (min/day) & 1.3 & -13.3 to 16.0 & 0.855 \\
\hline & Motorised transport $(\min / \text { day })^{*}$ & 0.895 & 0.772 to 1.038 & 0.142 \\
\hline & Motorised transport (days/week)* & 1.034 & 0.911 to 1.173 & 0.603 \\
\hline \multirow[t]{3}{*}{ Health clinics/services-presence } & NT sitting (min/day) & 12.7 & -25.7 to 51.0 & 0.506 \\
\hline & Motorised transport (min/day) ${ }^{\star}$ & 1.200 & 0.796 to 1.809 & 0.384 \\
\hline & Motorised transport (days/week)* & 0.974 & 0.711 to 1.336 & 0.872 \\
\hline \multirow[t]{3}{*}{ Places of worship-presence } & NT sitting (min/day) & 27.8 & 0.1 to 55.5 & 0.049 \\
\hline & Motorised transport $(\min / \text { day })^{*}$ & 0.840 & 0.634 to 1.115 & 0.230 \\
\hline & Motorised transport (days/week)* & 0.792 & 0.635 to 0.988 & 0.039 \\
\hline \multirow[t]{3}{*}{ Entertainment destinations-diversity } & NT sitting (min/day) & -0.5 & -16.8 to 15.7 & 0.949 \\
\hline & Motorised transport $(\mathrm{min} / \text { day })^{\star}$ & 0.991 & 0.809 to 1.215 & 0.934 \\
\hline & Motorised transport (days/week) ${ }^{\star}$ & 1.005 & 0.868 to 1.164 & 0.949 \\
\hline \multirow{3}{*}{ Public transit points-prevalence } & NT sitting (min/day) & -2.3 & -3.9 to -0.7 & 0.005 \\
\hline & Motorised transport (min/day) ${ }^{\star}$ & 1.012 & 0.975 to 1.050 & 0.527 \\
\hline & Motorised transport (days/week)* & 1.019 & 1.001 to 1.037 & 0.045 \\
\hline \multirow[t]{3}{*}{ Non-food retailers and services_-prevalence } & NT sitting (min/day) & -0.1 & -0.7 to 0.5 & 0.793 \\
\hline & Motorised transport (min/day) ${ }^{\star}$ & 1.003 & 0.994 to 1.010 & 0.546 \\
\hline & Motorised transport (days/week) ${ }^{\star}$ & 1.001 & 0.995 to 1.007 & 0.726 \\
\hline \multirow{3}{*}{ Food and grocery stores-prevalence } & NT sitting (min/day) & -0.1 & -1.1 to 0.9 & 0.804 \\
\hline & Motorised transport (min/day) ${ }^{\star}$ & 1.007 & 0.991 to 1.024 & 0.393 \\
\hline & Motorised transport (days/week) ${ }^{*}$ & 1.000 & 0.990 to 1.011 & 0.955 \\
\hline \multirow{3}{*}{ Restaurants-prevalence } & NT sitting (min/day) & 0.1 & -0.3 to 0.6 & 0.605 \\
\hline & Motorised transport (min/day) ${ }^{\star}$ & 1.001 & 0.993 to 1.009 & 0.866 \\
\hline & Motorised transport (days/week)* & 1.002 & 0.997 to 1.007 & 0.454 \\
\hline
\end{tabular}

negative at below average levels of path obstructions. No other significant moderating effects were found on nontransport sitting.

Significant interaction effects of prevalence of sloping streets and park presence on motorised transport were found (table 3), whereby positive associations of prevalence of sloping streets with motorised transport were found only in the absence of parks within a participant's neighbourhood. Also, park presence was negatively associated with motorised transport in areas with low levels of path obstructions, while the opposite was true in areas with above average levels of path obstructions. Finally, the prevalence of food/grocery stores in the neighbourhood was predictive of less motorised transport only in the absence of signs of crime/disorder.

\section{Associations of multiple destination variables with sitting} and motorised transport, and moderating effects of environmental characteristics

Models including all significant neighbourhood environmental characteristics, destination variables and interaction effects from the single-destination-variable models (presented above) could be estimated given that the intercorrelations between the variables were lower than 0.50 , indicating no multicollinearity problems. In the model for non-transport sitting, the effects of presence of places of worship ( $\mathrm{b}=38.9 ; 95 \%$ CI 10.0 to 67.9 ; $\mathrm{p}=0.010)$ and prevalence of public transit points $(\mathrm{b}=-4.2 ; 95 \% \mathrm{CI}-7.7$ to $-0.7 ; \mathrm{p}=0.020)$ remained statistically significant. While the interaction effect of entertainment destinations diversity by signs of crime/ disorder was no longer statistically significant $(b=17.8$; $95 \%$ CI -8.8 to $44.3 ; \mathrm{p}=0.183$ ), that of prevalence of food/grocery stores by path obstructions remained significant ( $b=0.10 ; 95 \%$ CI 0.05 to $0.15 ; \mathrm{p}<0.001)$, with prevalence of food/grocery stores showing a negative association with non-transport sitting only at $1 \mathrm{SD}$ below average levels of path obstructions $(b=-1.7 ; 95 \%$ CI -3.3 to $-0.1 ; \mathrm{p}=0.036)$.

All but the interaction effect of sloping streets by park presence remained statistically significant in the models of frequency and amount of motorised transport. Specifically, the presence of places of worship was predictive of lower frequency $\left(\mathrm{e}^{\mathrm{b}}=0.683 ; 95 \%\right.$ CI 0.557 to $0.837 ; \mathrm{p}<0.001$ ) and the prevalence of public transit point of higher frequency of motorised transport $\left(\mathrm{e}^{\mathrm{b}}=1.029 ; 95 \%\right.$ CI 1.002 to $\left.1.014 ; \mathrm{p}=0.009\right)$. Food/ grocery store prevalence was predictive of less frequency $\left(\mathrm{e}^{\mathrm{b}}=0.981 ; 95 \%\right.$ CI 0.968 to $\left.0.995 ; \mathrm{p}=0.005\right)$ and amount of motorised transport $\left(\mathrm{e}^{\mathrm{b}}=0.465 ; 95 \%\right.$ CI 0.456 to 


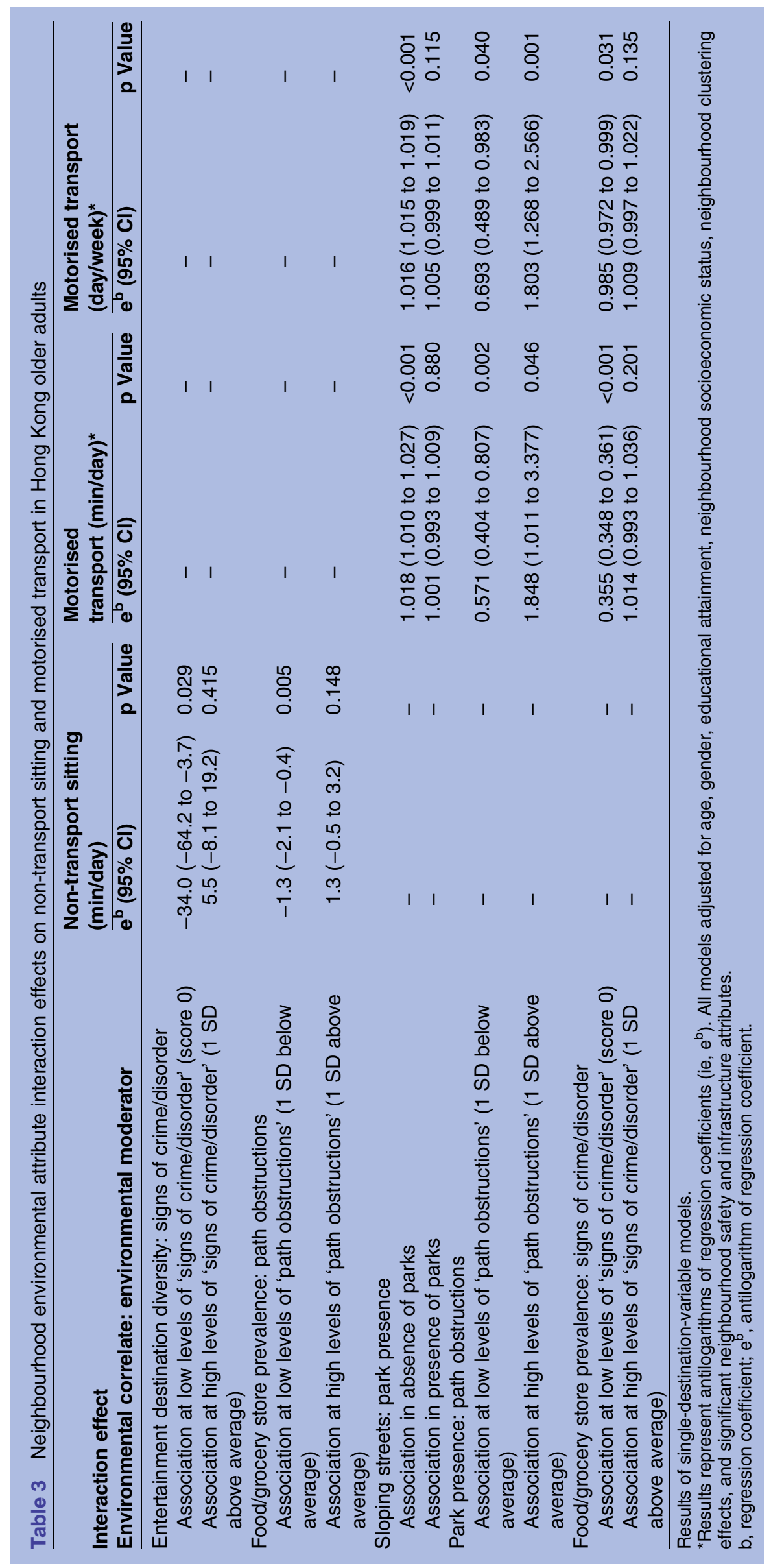


0.462; $\mathrm{p}<0.001$ ) only in the absence of signs of crime/ disorder. Park presence was positively associated with greater frequency of motorised transport at above average level of path obstructions only $\left(\mathrm{e}^{\mathrm{b}}=1.573 ; 95 \%\right.$ CI 1.074 to 2.304; $\mathrm{p}=0.020$ ), while it was negatively associated with amount of motorised transport only at below average levels of path obstructions $\left(\mathrm{e}^{\mathrm{b}}=0.636 ; 95 \%\right.$ CI 0.460 to $0.879 ; \mathrm{p}=0.006$ ).

\section{DISCUSSION}

Non-transport sitting time was found to be associated with a number of neighbourhood characteristics predictive of leisure-time physical activity and walking for different purposes. The majority of these associations (street lights, public facilities (benches and toilets) and sloping streets) were in the opposite direction than for walking (table 4). ${ }^{20} 2228$ The findings support the potential for non-transport sitting time to be affected by neighbourhood characteristics. With the exception of sloping streets, these characteristics can be modified with minimal impact on the urban form and at relatively low-cost, potentially reducing sitting time and its associated negative health outcomes in this population. The increases in intensity and possible risk of falls associated with walking up and down sloping streets may discourage walking, and could explain the positive relationships between sloping streets and both non-transport sitting time and frequency of use of motorised transport in older adults. They may stay at home or use public transport to avoid negotiating steep hills. The negative association of pedestrian safety with motorised transport supports improvements in pedestrian safety as a means of decreasing sitting time.
Associations were found for two destination measures: public transit points and places of worship. With more public transport points available, non-transport sitting time was lower and people travelled more often on motorised transport, but overall travel time was not greater. Therefore, the net outcome of a higher prevalence of public transit points may be a net decrease in total sitting time. Perhaps, counter-intuitively, presence of places of worship was positively associated with both non-transport sitting and walking for transport within the neighbourhood. ${ }^{22}$ This may be due to their encouraging walking, but also involving sedentary activities such as meeting others and performing sedentary religious rituals during visitation. Signs of crime/disorder, previously found to be positively correlated with transport-related walking ${ }^{22}$ and negatively related to walking for recreation, ${ }^{20}$ were negatively related to nontransport sitting. These relationships may be due to social disparities. ${ }^{29}$ Low SES residents are likely to find public transportation costs less affordable and therefore may engage in more transport-related walking, and spend more of their time outside of their home due to less favourable housing conditions. Moderating effects of environmental attributes on associations between presence/availability of destinations and sitting time were also found. In general, these suggested that a combination of neighbourhood features supportive of walking ${ }^{1922}{ }^{28}$ may at the same time discourage sitting.

This is the first study to examine the relationships of the neighbourhood environment with non-transport sitting time and motorised transport time in older adults. One other study has investigated some potential environmental correlates of one context in which sitting time occurs: TV viewing. ${ }^{17}$ Other strengths of the study

Table 4 Comparison of the relationships of environment measures with non-transport sitting, motorised transport and walking in Hong Kong older adults

\begin{tabular}{|c|c|c|c|}
\hline Measure & $\begin{array}{l}\text { Association with } \\
\text { non-transport sitting } \\
\text { time (current study) }\end{array}$ & $\begin{array}{l}\text { Association with } \\
\text { motorised transport } \\
\text { (current study) }\end{array}$ & $\begin{array}{l}\text { Association with walking } \\
\text { (previous publications with } \\
\text { the same population sample) }\end{array}$ \\
\hline Signs of crime/disorder ${ }^{\star}$ & - & & $\begin{array}{l}\text { + walking for transport, overall and within } \\
\text { neighbourhood }^{22} \\
\text { - walking for recreation }\end{array}$ \\
\hline Street lights $†$ & - & & $\begin{array}{l}\text { + walking for transport within the } \\
\text { neighbourhood }^{22}\end{array}$ \\
\hline Pedestrian safety & & $\begin{array}{l}\text { - (daily minutes) } \\
\text { - (frequency) }\end{array}$ & \\
\hline $\begin{array}{l}\text { Public facilities (benches } \\
\text { and public toilets)* }\end{array}$ & - & & $\begin{array}{l}\text { + walking for recreation }{ }^{20} \\
+ \text { walking for transport }\end{array}$ \\
\hline Sloping streets* & + & + (frequency) & $\begin{array}{l}\text { - walking for transport to retail and service } \\
\text { destinations }^{22}\end{array}$ \\
\hline Place of worship $†$ & + & + (frequency) & $\begin{array}{l}\text { + walking for transport within the } \\
\text { neighbourhood }\end{array}$ \\
\hline Public transit points* & - & + (frequency) & + overall walking for transport ${ }^{28}$ \\
\hline
\end{tabular}


are the objective audit-based determination of neighbourhood environmental attributes and the interviewadministered IPAQ-LC. The IPAQ was designed to assess activity levels across different countries, ${ }^{30}$ with the long form recommended for research, and is widely used to provide internationally comparable estimates of physical activity and sitting time. ${ }^{31}$ The cross-sectional nature of the study, which does not allow inferences of causality, was a limitation, as was the exclusive use of self-reports to assess non-transport sitting time and motorised transport. However, accurate objective alternatives to selfreports, such as activPAL, have not been deemed suitable for population studies. The IPAQ-LC was found to have acceptable test-retest reliability in Hong Kong older adults, but the association between non-transport sitting time and sedentary time estimated from accelerometry counts was low. ${ }^{23}$ While other studies have also found IPAQ-L sitting time to differ from accelerometerdetermined sedentary time, ${ }^{32} 33$ the difference was smaller when the IPAQ-L was interviewer-administered. ${ }^{34}$ In the current study, the IPAQ-LC was intervieweradministered, enabling clarification of components of sitting time, and guidance on question meaning was given by providing examples relevant to this population. Part of the reason for reported low associations of IPAC-L sitting time and accelerometer-estimated sedentary time may be explained by the exclusion of motorised transport in the determination of sitting time, which appears to account for around half the difference reported. ${ }^{23}{ }^{34}$ Other factors may also influence comparison with accelerometry counts when judging questionnaire validity. First, analysis of accelerometer counts to estimate total sedentary time using current methods can be inaccurate. ${ }^{35}$ Standing, a common occurrence when waiting for public transport and shopping at food markets in Hong Kong, is often misclassified as sitting, by accelerometry, ${ }^{36}$ but not with self-reported sitting time. Second, resting metabolic rate decreases with age in adults, ${ }^{37}$ therefore, so does the energy requirement of sedentary behaviour (sitting or reclining, waking behaviour with an energy expenditure $\leq 1.5 \mathrm{METs}^{38}$ ) in absolute terms. The commonly used accelerometer cut point of 100 counts per minute for sedentary behaviour was determined from a sample of adolescent girls ${ }^{39}$ and validated in 19 adults (mean age $=40.1$ years) ${ }^{40}$ Accelerometry cut points for sedentary time based on younger adult populations may overestimate sedentary time in older adults. Participation was limited to those with no mobility problems. Less mobile older adults may show different associations between the neighbourhood environment and sitting. None of the participants owned a car. Therefore, while giving up seats on public transport to older adults is a very strong ethos in Hong Kong, depending on the mode of public transport, motorised transport time may have included some standing time.

Owing to differences in study design, comparisons with the only other study to date looking at the associations of environmental attributes and a component of sedentary behaviour (TV viewing time) were limited. While many of the environmental attributes used in the study on TV time in Flemish older adults did not match those in our study, and different aspects of sedentary behaviour were assessed, ${ }^{17}$ street lighting was negatively related to sedentary behaviours in both studies. Also, neighbourhood safety was related to less sitting time in Flemish as well as in Hong Kong older adults. Lastly, feelings of unsafety was positively related to TV time in the Flemish population, and in Hong Kong, signs of crime and disorder, and pedestrian safety, two attributes of neighbourhood safety, were negatively associated with non-transport sitting and motorised transport, respectively. These findings suggest that some aspects of neighbourhood environments encouraging less sitting time in older adults may be common across countries.

The 306 average daily minutes of sitting time reported by participants in this study was similar to the IPAQ assessed mean sitting time of $300 \mathrm{~min}$ per day for 1865 -year-olds across 20 countries, but lower than the 360 min reported in a study for Hong Kong adults 2064 years of age ${ }^{41}$ A recent review of sedentary behaviour in older adults ( $\geq 60$ years) found a mean weighted average of $5.3 \mathrm{~h} /$ day $(318 \mathrm{~min} /$ day $)$ self-reported sitting time,${ }^{42}$ very similar to the current study. Daily sitting time in our participants was higher than the mean value of 264 min recently described in older German adults, where average daily sitting times were also lower than those of younger German adults. ${ }^{43}$ Furthermore, a multicountry study of adults' self-reported sitting time found that adults 40-65 years in most countries reported less sitting time than younger adults. ${ }^{41}$ The authors suggested "birth cohort effects based on greater use of technology, sedentary occupations, and use of passive modes of transport among younger adults" as possible reasons for this observation. ${ }^{41}$ Compared with younger adults, who may spend many hours in sedentary work environments and commuting, retired older adults aged $65+$, such as in the current study, would have more freedom to move around during this substantial period of the day.

Van Dyck et $a l,{ }^{16}$ using the same walkability/incomebased neighbourhood stratification as the present study, found self-reported (IPAQ) mean daily motorised transport in adults 20-65 years old from four cities in the USA, Australia and Belgium, ranged from 46.7 to $79.2 \mathrm{~min}$ per day. The motorised transport time in the current study was less than half of this. Possible reasons for lower motorised transport time in the Hong Kong older adult cohort include, (1) no work-related commuting, (2) the density of Hong Kong resulting in shorter distances to destinations, (3) preference for walking and (4) none of the participants owned a car, which is typical of older adults in Hong Kong where car numbers are very low $\left(61 / 1000\right.$ people) ${ }^{44}$ This sample reported $569 \mathrm{~min} /$ week of walking for transportation, ${ }^{22}$ that is, $1.35 \mathrm{~h} /$ day, indicating that walking is the most common 
mode of transport in this population, likely due to the above reasons.

Approximately 17000 older adults are Elderly Health Centre members. Elderly Health Centre members are representative of the general Hong Kong population of older adults in age, health status and SES. ${ }^{45}$ Our participants represented a random sample of older adults, members of the Elderly Health Centre, able to walk unassisted and with no diagnosed cognitive impairment, living in communities selected to maximise the range of exposures (walkability and SES) and outcomes (walking). Given the adopted sampling strategy, they do not represent the entire Hong Kong population of older adults.

Studies in other locations are needed to inform the generalisability of the observed environmental correlates of sitting time. Future research needs to examine populations of older adults who are not perfectly mobile. Also, future studies need to employ objective measures and/or more detailed, contextually specific self-report measures of sedentary behaviour (eg, TV watching, internet surfing, talking on the phone while sitting). They also need to examine the independent contribution of different factors at various levels of influence (individual, social, environmental and policy) on older adults' sedentary behaviour, following a socioecological approach.

\section{CONCLUSION}

Sedentary behaviour, primarily sitting time, is a public health concern. While sitting time has been associated with non-communicable diseases, little is known about the effect of the environment on sitting time in older adults. This investigation showed associations of nontransport sitting time and motorised transport time with objectively measured characteristics in Hong Kong older adults' neighbourhood environment, with a number of these associations in the opposite direction to those previously found for recreational and transport-related walking. Some of these environmental characteristics, such as street lighting, public toilets, benches, path obstructions, pedestrian safety and public transit points, can be modified with minimal impact on the urban form and at relatively low-cost, potentially reducing sitting time and its associated negative health outcomes in this population. Diversity of destinations in the neighbourhood may also be important in helping reduce sitting in older adults, but to have an impact, such destinations need to be situated in safe and accessible environments. These findings have potential implications for urban planning policymakers concerned with reducing population levels of sedentary behaviour, a public health concern.

Contributors $A B$ and $E C$ wrote the manuscript. $E C$ performed the data analysis. $A B, E C, C S-K C, J M J$ and RSYL participated in the conceptualisation of the manuscript, contributed to critical revision and approved the final version.
Funding This work was supported by the Health and Health Service Research Fund (Food and Health Bureau, Government of the Hong Kong SAR) grant no. 04060671. EC is supported by an Australian Research Council Future Fellowship (FT140100085).

Competing interests None declared.

Ethics approval Department of Health Ethics Committee (Hong Kong SAR) and the Human Research Ethics Committee for Non-Clinical Faculties of the University of Hong Kong.

Provenance and peer review Not commissioned; externally peer reviewed.

Data sharing statement This study used data from clients of the Elderly Health Services, Department of Health, Hong Kong. Access to the data is limited by the Department of Health, Hong Kong, to staff of the Department of Health and the research investigators.

Open Access This is an Open Access article distributed in accordance with the Creative Commons Attribution Non Commercial (CC BY-NC 4.0) license, which permits others to distribute, remix, adapt, build upon this work noncommercially, and license their derivative works on different terms, provided the original work is properly cited and the use is non-commercial. See: http:// creativecommons.org/licenses/by-nc/4.0/

\section{REFERENCES}

1. Henson J, Yates T, Edwardson CL, et al. Sedentary time and markers of chronic low-grade inflammation in a high risk population. PLOS ONE 2013:8:e78350.

2. Shen D, Mao W, Liu T, et al. Sedentary behavior and incident cancer: a meta-analysis of prospective studies. PLoS ONE 2014;9: e105709.

3. Asztalos M, Cardon G, De Bourdeaudhuij I, et al. Cross-sectiona associations between sitting time and several aspects of mental health in Belgian adults. J Phys Act Health 2014 Published Online First 28 Sep 2014. doi:10.1123/jpah.2013-0513

4. Chastin SFM, Mandrichenko O, Helbostadt JL, et al. Associations between objectively-measured sedentary behaviour and physical activity with bone mineral density in adults and older adults, the NHANES study. Bone 2014;64:254-62.

5. Gianoudis J, Bailey CA, Daly RM. Associations between sedentary behaviour and body composition, muscle function and sarcopenia in community-dwelling older adults. Osteoporos Int 2015;26:571-9.

6. Hawkins M, Newman AB, Madero M, et al. TV watching, but not physical activity, is associated with change in kidney function in older adults. J Phys Act Health 2014. Published Online First 25 Jan 2014. doi:10.1123/jpah.2013-0289

7. Rezende LFMd, Rey-López JB, Matsudo VKR, et al. Sedentary behavior and health outcomes among older adults: a systematic review. BMC Public Health 2014;14:333.

8. Steinberg SI, Sammel MD, Harel BT, et al. Exercise, sedentary pastimes, and cognitive performance in healthy older adults. Am J Alzheimers Dis Other Demen 2014. Published Online First 5 Aug 2014.

9. Healy GN, Matthews CE, Dunstan DW, et al. Sedentary time and cardio-metabolic biomarkers in US adults: NHANES 2003-06. Eur Heart J 2011;32:590-7.

10. Mansoubi M, Pearson N, Biddle SJH, et al. The relationship between sedentary behaviour and physical activity in adults: a systematic review. Prev Med 2014;69:28-35.

11. Owen N, Salmon J, Koohsari MJ, et al. Sedentary behaviour and health: mapping environmental and social contexts to underpin chronic disease prevention. Br J Sports Med 2014;48:174-7.

12. Durand $\mathrm{CP}$, Andalib M, Dunton GF, et al. A systematic review of built environment factors related to physical activity and obesity risk: implications for smart growth urban planning. Obes Rev 2011;12: e173-82.

13. Van Cauwenberg J, De Bourdeaudhuij I, De Meester F, et al. Relationship between the physical environment and physical activity in older adults: a systematic review. Health Place 2011;17:458-69.

14. Van Holle V, Deforche B, Van Cauwenberg J, et al. Relationship between the physical environment and different domains of physical activity in European adults: a systematic review. BMC Public Health 2012;12:807.

15. Owen N, Healy GN, Matthews CE, et al. Too much sitting: the population health science of sedentary behavior. Exerc Sport Sci Rev 2010;38:105-13.

16. Van Dyck D, Cerin E, Conway TL, et al. Associations between perceived neighborhood environmental attributes and adults' 
sedentary behavior: findings from the USA, Australia and Belgium. Soc Sci Med 2012;74:1375-84.

17. Van Cauwenberg J, De Donder L, Clarys $\mathrm{P}$, et al. Relationships of individual, social, and physical environmental factors with older adults' television viewing time. J Aging Phys Act 2014;22:508-17.

18. Berrigan D, Fulton JE, Galuska DA, et al. Vital signs: walking among adults-United States, 2005 and 2010. MMWR Morb Mortal Wkly Rep 2012;61:595-601.

19. Lee PH, Nan H, Yu Y-Y, et al. For non-exercising people, the number of steps walked is more strongly associated with health than time spent walking. J Sci Med Sport 2013;16:227-30.

20. Cerin E, Lee K-Y, Barnett A, et al. Objectively measured neighborhood environments and leisure-time physical activity in Chinese urban elders. Prev Med 2013;56:86-9.

21. Cerin E, Sit CHP, Barnett A, et al. Walking for recreation and perceptions of the neighborhood environment in older Chinese urban dwellers. J Urban Health 2013;90:56-66.

22. Cerin E, Lee K-Y, Barnett A, et al. Walking for transportation in Hong Kong Chinese urban elders: a cross-sectional study on what destinations matter and when. Int J Behav Nutr Phys Act 2013;10:78.

23. Cerin E, Barnett $A$, Cheung M-C, et al. Reliability and validity of the IPAQ- $L$ in a sample of Hong Kong urban older adults: does neighborhood of residence matter? J Aging Phys Act 2012;20:402-20.

24. Cerin E, Sit CHP, Cheung M-A, et al. Reliable and valid NEWS for Chinese seniors: measuring perceived neighborhood attributes related to walking. Int J Behav Nutr Phys Act 2010;7:84.

25. Cerin E, Chan KW, Macfarlane DJ, et al. Objective assessment of walking environments in ultra-dense cities: development and reliability of the Environment in Asia Scan Tool-Hong Kong version (EAST-HK). Health Place 2011;17:937-45.

26. Cerin E, Barnett A, Sit CHP, et al. Measuring walking within and outside the neighborhood in Chinese elders: reliability and validity. BMC Public Health 2011;11:851.

27. Aiken LS, West SG. Multiple regression: testing and interpreting interactions. Newbury Park: Sage Publications, 1991.

28. Cerin E, Sit CHP, Barnett A, et al. Ageing in an ultra-dense metropolis: perceived neighbourhood characteristics and utilitarian walking in Hong Kong elders. Public Health Nutr 2014;17:225-32.

29. Cerin E, Mellecker R, Macfarlane DJ, et al. Socioeconomic status, neighborhood characteristics, and walking within the neighborhood among older Hong Kong Chinese. J Aging Health 2013;25:1425-44.

30. Craig CL, Marshall AL, Sjöström M, et al. International Physical Activity Questionnaire: 12-country reliability and validity. Med Sci Sports Exerc 2003;35:1381-95.

31. van Poppel MNM, Chinapaw MJM, Mokkink LB, et al. Physical activity questionnaires for adults: a systematic review of measurement properties. Sports Med 2010;40:565-600.
32. Celis-Morales CA, Perez-Bravo F, Ibañez L, et al. Objective vs. self-reported physical activity and sedentary time: effects of measurement method on relationships with risk biomarkers. PLOS ONE 2012;7:e36345

33. Hagstromer M, Ainsworth BE, Oja P, et al. Comparison of a subjective and an objective measure of physical activity in a population sample. J Phys Act Health 2010;7:541-50.

34. Van Dyck D, Cardon G, Deforche B, et al. IPAQ interview version: convergent validity with accelerometers and comparison of physical activity and sedentary time levels with the self-administered version. J Sports Med Phys Fitness 2014. Published Online First 11 Jun 2014.

35. Lyden K, Keadle SLK, Staudenmayer JW, et al. Validity of two wearable monitors to estimate breaks from sedentary time. Med Sci Sports Exerc 2012:44:2243-52.

36. de Vries SI, Galindo Garre F, Engbers LH, et al. Evaluation of neural networks to identify types of activity using accelerometers. Med Sci Sports Exerc 2011;43:101-7.

37. Ferrucci L, Schrack JA, Simonsick EM, et al. Aging and the energetic cost of life. J Am Geriatr Soc 2012;60:1768-9.

38. Sedentary Behaviour Research Network. Letter to the editor: standardized use of the terms "sedentary" and "sedentary behaviours". Appl Physiol Nutr Metab 2012;37:540-2.

39. Treuth MS, Schmitz K, Catellier DJ, et al. Defining accelerometer thresholds for activity intensities in adolescent girls. Med Sci Sport Exerc 2004;36:1259-66.

40. Matthews CE, Chen KY, Freedson PS, et al. Amount of time spent in sedentary behaviors in the United States, 2003-2004. Am J Epidemiol 2008;167:875-81.

41. Bauman A, Ainsworth BE, Sallis JF, et al. The descriptive epidemiology of sitting: a 20-country comparison using the International Physical Activity Questionnaire (IPAC). Am J Prev Med 2011;41:228-35.

42. Harvey JA, Chastin SFM, Skelton DA. How sedentary are older people? A systematic review of the amount of sedentary behaviour. J Aging Phys Act 2014. Published Online First 11 Nov 2014. doi:10.1123/japa.2014-0164

43. Wallman-Sperlich B, Bucksch J, Hansen S, et al. Sitting time in Germany: an analysis of sociodemographic and environmental correlates. BMC Public Health 2013;13:196.

44. The World Bank. Cross Country Data, Hong Kong SAR, China, Passenger cars (per 1,000 people). https://www.quandl.com/data/ WORLDBANK/HKG_IS_VEH_PCAR_P3-Hong-Kong-SAR-ChinaPassenger-cars-per-1-000-people (accessed 24 Mar 2015).

45. Schooling CM, Lam TH, Li ZB, et al. Obesity, physical activity, and mortality in a prospective Chinese elderly cohort. Arch Intern Med 2006;166:1498-504. 